\title{
Análise espacial dos fatores determinantes das pastagens no baixo Amazonas/PA
}

O presente trabalho teve por objetivo analisar a dinâmica espacial de áreas de pastagens e verificar os principais fatores que contribuem para sua distribuição na região do Baixo Amazonas nos anos de 2000 e 2014. Foi utilizada análise de regressão espacial sendo as porcentagens de pastagem como variáveis dependentes e, como variáveis independentes, fatores ambientais, de acessibilidade, políticas públicas, estrutura fundiária, economia e demográficos relacionados com a presença de pastagens. Observou-se que as áreas de pastagem em 2000 eram de 15.767,12 Km² enquanto que em 2014 aumentou para $18.657,58$ Km². Além disso, os resultados mostraram que as áreas de pastagens naturais ainda são em maior proporção que áreas de pastagens cultivadas com um incremento de $0,23 \%$ em 2014 quando comparado com o ano 2000, porém as pastagens plantadas apresentaram crescimento em 11,64\% de área. A concentração das pastagens naturais estão próximas a planície de inundação, enquanto que a expansão das pastagens plantadas ocorrem em áreas com presença de estradas e rodovias. Os resultados da análise de regressão mostraram que a porcentagem de área com a agricultura e precipitação anual foram as variáveis explicativas que se relacionaram nos dois anos para os dois tipos de pastagens. Para as pastagens plantadas a variável explicativa mais significativa foi os estabelecimentos agropecuários com pecuária com coeficiente de -0,37 e 0,24 em 2000 e 2014, respectivamente. Verificou-se que o estabelecimento de áreas protegidas são cruciais pois atuam como barreiras para a expansão das áreas de pastagens plantadas e que, estradas e rodovias favorecem a implantação de pastagens em seu entorno. A modelagem estatística e espacialmente explícita mostrou ser uma ferramenta útil de análise para compreender os processos e padrões de mudanças de uso e cobertura da terra, em específico a distribuição das pastagens no Baixo Amazonas.

Palavras-chave: Pastagens; Baixo Amazonas; Regressão Espacial.

\section{Spatial analysis of pastures determinants in the lower Amazon/PA}

This study aimed to analyze the spatial dynamics of pastures areas and check the main factors that contribute to its distribution in the Lower Amazon region in 2000 and 2014. Spatial regression analysis was used, with pasture percentages as dependent variables and, as independent variables, environmental, accessibility, public policies, land structure, economy and demographic variables related to the presence of pasture as independent variables. It was observed that pasture areas in 2000 were $15,767.12 \mathrm{~km}^{2}$ while in 2014 it increased to $18,657.58 \mathrm{~km}^{2}$. In addition, the results showed that the natural pasture areas are still in greater proportion than pasture areas cultivated with an increment of $0.23 \%$ in 2014 when compared with the year 2000 , however the planted pastures presented growth in $11.64 \%$ of area. The concentration of natural pastures is close to the flood plain, while the expansion of planted pastures occurs in areas with roads and highways. The results of the regression analysis showed that the percentage of area with agriculture and annual precipitation were the explanatory variables that were related in the two years for the two types of pastures. For the planted pastures the most significant explanatory variable was the agricultural establishments with livestock with coefficient of -0.37 and 0.24 in 2000 and 2014, respectively. It was verified that the establishment of protected areas are crucial because they act as barrier for the expansion of pasture areas planted and that, roads and highways favor the implantation of pastures in its surroundings. Statistical and spatially explicit modeling proved to be a useful analysis tool to understand the processes and patterns of land use change and land cover, in particular the distribution of pastures in the Lower Amazon.

Keywords: Pastures; Lower Amazon; Spatial Regression.

Topic: Tecnologia, Modelagem e Geoprocessamento

Reviewed anonymously in the process of blind peer.

Jéssica Ariana de Jesus Corrêa (iD

Universidade Federal do Oeste do Pará, Brasil

http://lattes.cnpq.br/7180510909867481

http://orcid.org/0000-0002-2691-6020

jehssicorrea@yahoo.com.br

José Laurindo Campos dos Santos (iD

Instituto Nacional de Pesquisas da Amazônia, Brasil

http://lattes.cnpq.br/8582991885434941

http://orcid.org/0000-0001-5363-8225

laurocampos2004@gmail.com

Silvia Cristina de Pádua Andrade (it

Instituto Federal de Educação, Ciência e Tecnologia do Amazonas http://lattes.cnpq.br/5086189027878863

http://orcid.org/0000-0002-2787-6825

silviacris@gmail.com

d

DOI: 10.6008/CBPC2179-6858.2018.005.0030
Received: 10/06/2018

Approved: 24/07/2018

\author{
zaura Cristina Nunes Pereira Costa \\ Universidade Federal do Oeste do Pará, Brasil \\ http://lattes.cnpq.br/1611384978629669 \\ http://orcid.org/0000-0001-9121-6680 \\ geoiza@gmail.com \\ Júlio Tota da Silva \\ Universidade Federal do Oeste do Pará, Brasi \\ http://lattes.cnpq.br/3850475880747662 \\ http://orcid.org/0000-0003-4093-6586 \\ totaju@gmail.com
}

Referencing this:

CORRÊA, J. A. J.; SANTOS, J. L. C.; ANDRADE, S. C. P.; COSTA, I. C. N. P.; SILVA, J. T.. Análise espacial dos fatores determinantes das pastagens no baixo Amazonas/PA. Revista Ibero Americana de Ciências Ambientais, v.9, n.5, p.341-351, 2018. DOI:

http://doi.org/10.6008/CBPC2179-6858.2018.005.0030 


\section{INTRODUÇÃO}

As pastagens, em um sentido mais amplo de acordo com a FAO (2005), ocupam 40,5\% da cobertura da superfície terrestre. Esse ecossistema tem diversas funções e serviços tais como conservação do solo, ciclagem de nutrientes e diversidade biológica (SALA et al., 1997). Embora desempenhem tais funções as pastagens têm sido comumente definidas em relação ao seu papel na produção agropecuária devido ser importante fonte de alimento para produção animal. Neste sentido tem se mostrado dinâmico devido as mudanças e conversões entre tipos de sistemas naturais para pastagens de alta intensidade através das mudanças no uso da terra (BALDI et al., 2008, COSTA et al., 2015, PHELPS et al., 2017).

No Brasil um total de 172,3 milhões de hectares de pastagens (naturais e plantadas) estão distribuídas no território nacional de acordo com o último censo agropecuário de 2006 (DIAS-FILHO, 2014). Desse total 36\%, aproximadamente 60 milhões de hectares, correspondem a pastagem natural, que vem decrescendo seu percentual desde a década de 1970 em detrimento de lavouras, pastagens plantadas e outros tipos de uso da terra, conforme dados apontados pelo IBGE. A substituição para pastagens cultivadas tem sido imprescindível à produção de carne bovina no país, que é o segundo maior produtor do mundo e primeiro exportador de carne bovina (AGUIAR et al., 2017; USDA, 2018), pois utiliza as áreas de pastagens na pecuária extensiva para a criação de rebanhos.

As condições das pastagens são responsáveis pela produtividade da pecuária brasileira, incluindo nesse processo o manejo adequado do pastejo. Além disso, a degradação das pastagens é outro problema que afeta o sistema produtivo sendo um fator limitante ao aumento da produtividade da pecuária (AGUIAR et al., 2017). A capacidade de suporte das pastagens varia de uma região para outra de acordo com determinadas características que proporcionam o crescimento das espécies forrageiras, como por exemplo, as condições climáticas temperatura do ar e precipitação.

Esses fatores apresentam-se na literatura como determinantes na implantação de pastagens cultivadas, por exemplo, existem espécies que exigem altas temperaturas, como em torno de $30^{\circ} \mathrm{C}$, e chuvas abundantes para obter altas taxas de crescimento (ZIMER et al., 2012). A região Norte se enquadra nessas características apresentando-se região adequada, em termos climáticos, para a produção de pastagens cultivadas. De acordo com Dias-Filho (2014), nessa sub-região as áreas de pastagens cultivadas superam as naturais, com exceção do Estado do Amapá.

Na Amazônia os processos de mudanças no uso e cobertura da terra tem se alterado devido a expansão da fronteira econômica e territorial, exemplo disso são os programas de investimento que propiciam condições para mudanças rápidas (THERY, 2005; SILVA et al., 2013), resultando em diferentes características em termos de distribuição e tipos de uso da terra. Dentro desse contexto, as pastagens apresentam diferentes distribuições e padrões, que são determinados pelas características de cada localização geográfica e territorial. Nesse sentido, identificar quais fatores são determinantes para a dinâmica dessa classe produtiva de uso da terra, torna-se importante não somente pela produtividade econômica, mas também aquelas de escopo ambiental. 
Para isso diversos estudos têm utilizado técnicas e ferramentas de análise espacial no sentido de localizar mudanças ocorridas no uso e cobertura da terra através do mapeamento de variáveis espacialmente explícitas e identificar quais os condutores dessas mudanças. Modelos de regressão espacial foram aplicados em diferentes tipos de uso e cobertura da terra. Aguiar et al. (2007) analisou os fatores do desmatamento na Amazônia brasileira utilizando modelos de regressão simples e modelo de regressão espacial (Spatial Lag model - SAR), Espindola et al. (2012) analisou os determinantes da agricultura na Amazônia brasileira e, Silva e Li (2017) os determinantes da expansão urbana na cidade de Praia em Cabo Verde, mostrando assim a aplicabilidade do uso de ferramentas espaciais e modelos em todos os tipos de aplicações envolvendo as classes de uso e cobertura da terra.

As pastagens por serem uma classe de uso e cobertura da terra, que vem apresentando mudanças em sua dinâmica, pode ser objeto de análise como um esforço de compreensão dos seus processos e padrões, começando pela identificação dos fatores que influenciam as mudanças entre os tipos naturais e cultivadas. Nesse sentido, o presente estudo analisa a distribuição espacial das pastagens na região do Baixo Amazonas, especificamente nos anos de 2000 e 2014, além de verificar os potenciais fatores determinantes para a dinâmica dos diferentes tipos.

\section{METODOLOGIA}

\section{Área de estudo}

A Mesorregião do Baixo Amazonas (Figura 1) está localizado na porção noroeste do Estado do Pará com área de aproximadamente 340 mil km² (IBGE, 2010), correspondendo a $25 \%$ da área do estado, na Amazônia Central. O Baixo Amazonas é composto por 15 municípios: Alenquer, Almeirim, Belterra, Curuá, Faro, Juruti, Mojuí dos Campos, Monte Alegre, Óbidos, Oriximiná, Placas, Porto de Moz, Prainha, Santarém e Terra Santa. Essa região por sua diversidade tem apresentado um histórico contínuo de exploração e, consequente alteração da paisagem por atividades antrópicas (CAMPHORA, 2016) entre os quais destaca-se o uso das pastagens naturais, principalmente da região de várzea (SHEIKH et al., 2006), para a criação bovina e mais recentemente a expansão e intensificação da plantação de pastagens cultivadas.

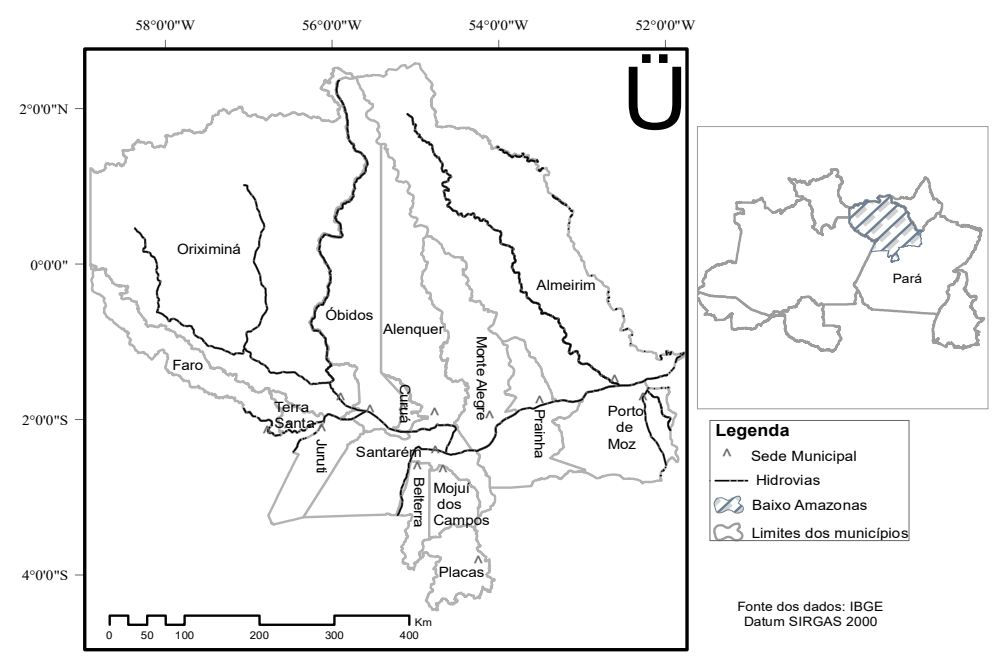

Figura 1: Localização da Mesorregião do Baixo Amazonas/PA. 


\section{Dados espaciais}

\section{Variáveis Dependentes}

Utilizou-se as classes de pastagens do mapeamento do uso e cobertura da terra do IBGE (IBGE, 2016) dos anos de 2000 e 2014. Nesse mapeamento existem duas classes de pastagem: pastagem natural e pastagem plantada, que foram representadas por meio da porcentagem de área ocupada por essas classes.

\section{Variáveis Independentes - Fatores Determinantes}

As variáveis selecionadas são aquelas que estão potencialmente associadas as pastagens tendo como base a literatura pertinente (AGUIAR et al., 2007; RIVERO et al., 2009; XIE et al., 2012; ZIMER et al., 2012; DIAS-FILHO, 2014) e a disponibilidade de dados oficiais e de qualidade. Dessa forma, foram selecionadas 22 variáveis que poderiam, potencialmente, explicar a dinâmica das pastagens naturais e plantadas no baixo Amazonas por meio da facilitação ou impedimento. Cada uma dessas variáveis tem associado conceitos relacionados a variável dependente e foram subdividas em quatro fatores subjacentes (conforme Tabela 1): Demográfica - Densidade populacional, Índice de Desenvolvimento Humano Municipal - IDHM, índice de Gini de renda; Estrutura Fundiária - Índice de Gini da estrutura agrária e Porcentagem de estabelecimentos agropecuários com pecuária; Políticas públicas: Projetos de assentamentos (PA, PDS, PEAE), Áreas protegidas (por tipo de unidade) e terras indígenas; Econômico: Produto Interno Bruto - PIB; Acessibilidade Proximidade a cidades, Distância estradas, Distância a vilas, Distância a hidrovias, Distancias a rodovias, Distância a portos; e Ambiental: precipitação e degradação florestal. O mapa de algumas variáveis explanatórias pode ser visto na Figura 2.

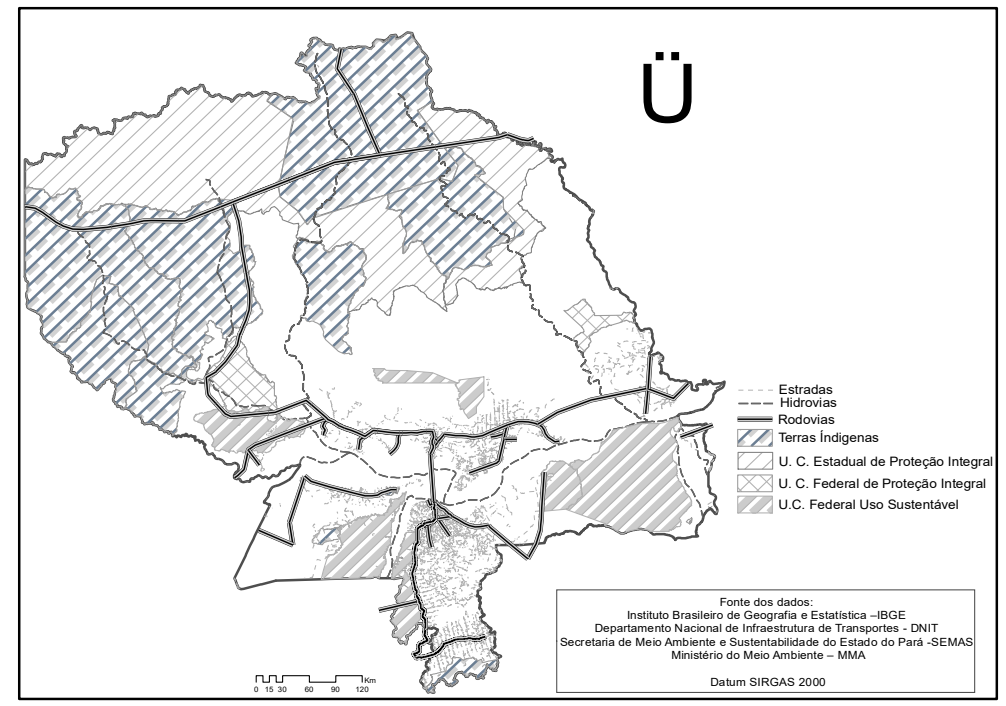

Figura 2: Distribuição Espacial dos potenciais fatores determinantes das pastagens no Baixo Amazonas (PA).

Buscou-se dados das variáveis independentes em anos mais próximos dos dados de pastagens com a finalidade de captar as relações no tempo próximo, por exemplo dados do censo agropecuário de 1996 e 2006 para os dados pastagem de 2000 e 2014, respectivamente. Dados que não possuem disponibilidade 
temporal foram utilizados para analise nos dois períodos, como por exemplo, as rodovias do Departamento Nacional de Infraestrutura de Transportes (DNIT).

Tabela 1: Lista dos potenciais fatores associados a pastagens no Baixo Amazonas/PA.]

\begin{tabular}{|c|c|c|c|c|}
\hline Dimensões & Variáveis & Descrição & Unidade & Fonte \\
\hline \multirow[t]{3}{*}{ Demográfica } & IDHM & $\begin{array}{l}\text { Índice de desenvolvimento Humano Municipal para } \\
2000 \text { e 2010, composto por três dimensões de } \\
\text { desenvolvimento humano: longevidade, educação e } \\
\text { renda. }\end{array}$ & - & PNUD \\
\hline & Gini - renda & Distribuição de renda municipal em 2000 e 2010 & - & IBGE \\
\hline & Densidade populacional & Densidade populacional rural e urbana em 2000 e 2010 & $\mathrm{Hab} . / \mathrm{Km}^{2}$ & IBGE \\
\hline \multirow{2}{*}{$\begin{array}{l}\text { Estrutura } \\
\text { Fundiária }\end{array}$} & Gini - Estrutura agrária & Distribuição de terras em 1996 e 2006 & - & IBGE \\
\hline & $\begin{array}{l}\text { Estabelecimentos } \\
\text { agropecuários com } \\
\text { pecuária }\end{array}$ & $\begin{array}{l}\text { Estabelecimentos agropecuários com pecuária em } \\
\text { 1995/96 e } 2006\end{array}$ & $\%$ & IBGE \\
\hline Econômico & PIB & Produto Interno Bruto Municipal em 2000 e 2010 & $\mathrm{R} \$ \times 1000$ & SIDRA/IBGE \\
\hline \multirow[t]{3}{*}{$\begin{array}{l}\text { Políticas } \\
\text { Públicas }\end{array}$} & $\begin{array}{l}\text { Projetos } \\
\text { Assentamentos }\end{array}$ & $\begin{array}{l}\text { Projetos de assentamentos (PA, PDS, PEAE) desde } \\
2000\end{array}$ & $\begin{array}{l}\text { \% da área } \\
\text { da célula }\end{array}$ & INCRA \\
\hline & Terras Indígenas & Terras indígenas & $\begin{array}{l}\text { \% da área } \\
\text { da célula }\end{array}$ & FUNAI \\
\hline & Áreas protegidas & $\begin{array}{l}\text { Unidades de Conservação de Uso Sustentável e } \\
\text { Unidades de Conservação de Proteção Integral }\end{array}$ & $\begin{array}{l}\text { \% da área } \\
\text { da célula }\end{array}$ & MMA \\
\hline \multirow[t]{5}{*}{ Acessibilidade } & Portos & Distância a portos mais próximos & $\mathrm{Km}$ & PNLT \\
\hline & Rodovias & Distância as rodovias (federais e estaduais). & $\mathrm{Km}$ & DNIT \\
\hline & Estradas & Porcentagem de estradas. & $\%$ & SEMA/PA \\
\hline & Cidades e vilas & Distância aos núcleos mais próximas & $\mathrm{Km}$ & INDE \\
\hline & Hidrovias & Distância aos principais rios & & PNLT \\
\hline \multirow[t]{2}{*}{ Ambiental } & Precipitação & Precipitação anual acumulada & $\mathrm{mm}$ & WorldClim \\
\hline & Degradação florestal & Áreas degradadas em 2007 e 2013 & $\%$ & $\begin{array}{l}\text { Degrad } \\
\text { /INPE }\end{array}$ \\
\hline
\end{tabular}

\section{Método}

Testou-se a correlação de Spearman entre todas as variáveis independentes em que se estabeleceu um valor crítico $\geq 60 \%$ de correlação entre as variáveis independentes para eliminar a multicolinearidade das variáveis entre si. Além disso, esse mesmo teste foi usado para verificar a correlação entre a variável dependente e os fatores potenciais. A Figura 3 apresenta o fluxograma da metodologia adotada para a escolha e análise estatística dos fatores determinantes potencias da dinâmica de pastagens no Baixo Amazonas.

\section{Modelo de Regressão Spatial Lag Model (SAR)}

O comportamento de dados de uso e cobertura da terra, no geral, tem tendências de ser espacialmente correlacionados o que violaria o pressuposto da regressão linear simples de independência dos dados. O índice de Moran (I) é um teste utilizado para confirmar a existência de autocorrelação espacial. O Índice de Moran é um índice global, que varia de -1 a 1, e indica a dependência espacial dos dados. Valores mais próximos a -1 indicam dados com forte autocorrelação negativa ou inversa. Valores mais próximos a 1 indicam dados com forte autocorrelação positiva ou direta e valores próximos a 0 indicam aleatoriedade. 


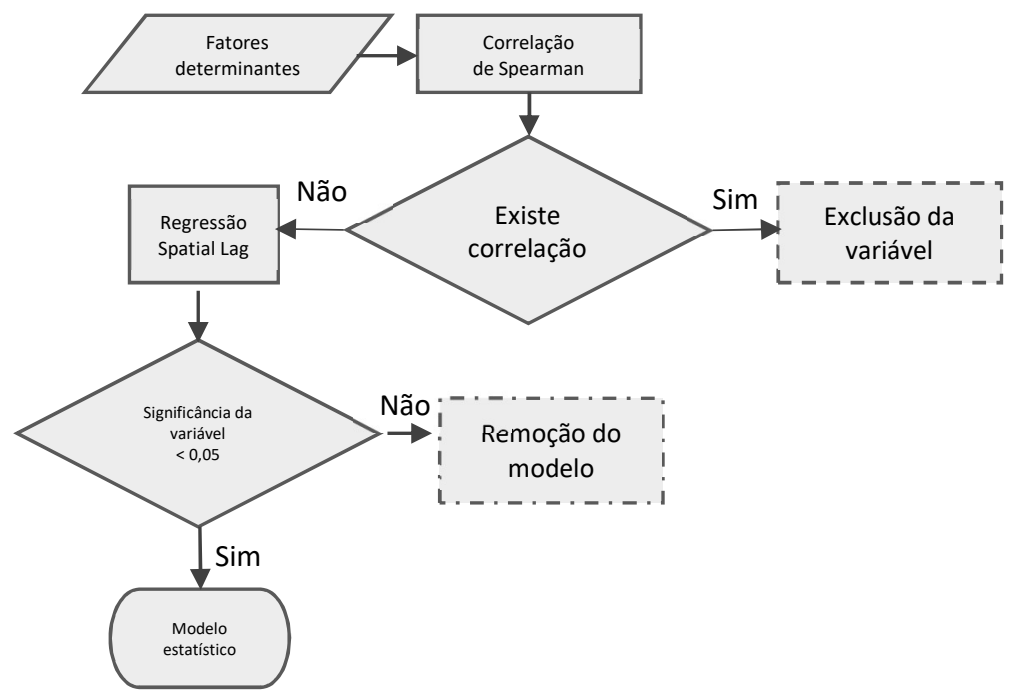

Figura 3: Fluxograma da análise de regressão dos fatores determinantes potenciais.

Devido a autocorrelação espacial realizou-se a o modelo de regressão Spatial Lag Model (SAR) para verificar a importância relativa de fatores explanatórios potenciais. O SAR é um modelo de regressão linear modificado para capturar a dependência espacial em um parâmetro (o denominado coeficiente autorregressivo). O SAR inclui um termo de dependência espacial, através de um novo termo que incorpora a autocorrelação espacial como parte de um componente explanatório do modelo, conforme Equação 1.

$$
Y=\rho W Y+X \beta+\varepsilon
$$

Onde: $\rho=$ coeficiente autoregressivo espacial - medida de correlação espacial $\mathrm{W}=$ matriz de proximidade espacial $\mathrm{WY}=$ expressa $\mathrm{a}$ dependência espacial em $\mathrm{Y}$ $\varepsilon=$ resíduos do modelo

Todas os procedimentos e análises foram realizadas nos softwares QGIS (construção de variáveis espacialmente explícitas), R (análise exploratória dos dados), GEODA (Índice de Moran e Modelo Spatial Lag) e LibreOffice Calc (tabulação e construção de gráficos e tabelas).

\section{RESULTADOS}

\section{Pastagens no Baixo Amazonas/PA}

A figura 4 apresenta a distribuição das pastagens no Baixo Amazonas entre 2000 e 2014. Observa-se que áreas de pastagens apresentam uma concentração próximos aos rios, rodovias e estradas, principalmente as pastagens plantadas. Além disso, é possível verificar um crescimento e espalhamento das áreas de pastagens plantadas em 2014.

O total de área e seu percentual de cobertura de pastagens é mostrado na tabela 2 . Do total de $349.888 \mathrm{~km}^{2}$ da área do Baixo Amazonas, $15.767,12$ e 18.657,58 são pastagens em 2000 e 2014, respectivamente. As áreas de pastagens naturais apresentaram área de 12.161,94 Km² em 2000 e 12.218, 94 $\mathrm{Km}^{2}$ em 2014, já as pastagens plantadas $3.605,184 \mathrm{Km}^{2}$ e $6.438 \mathrm{Km}^{2}$, respectivamente. Observa-se que ambos os tipos de pastagens apresentaram crescimento de áreas em 2014, naturais com 0,23 \% e plantadas de 11,64 \%. Não é possível determinar quais são as trajetórias e os tipos de conversões, mas esse resultado 
demonstra que existe uma dinâmica acentuada com outros usos e coberturas devido ao crescimento de ambos os tipos de pastagens que possivelmente é resultado da modificação/conversão com outras classes.

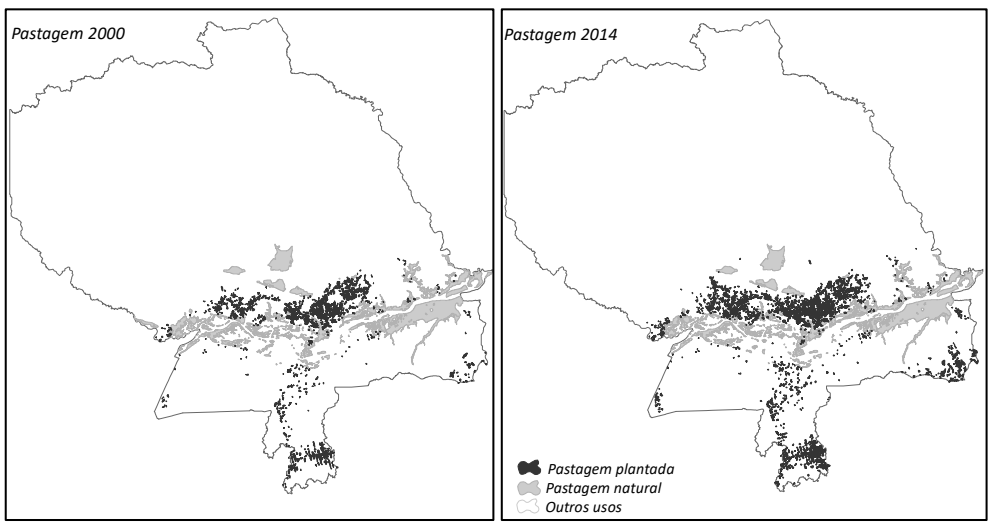

Figura 4: Pastagens naturais e plantadas em 2000 e 2014 no Baixo Amazonas.

Tabela 2: Mudanças nas áreas de pastagens no Baixo Amazonas em 2000 e 2014.

\begin{tabular}{|l|l|l|l|l|l|}
\hline & $\mathbf{2 0 0 0}$ & & $\mathbf{2 0 1 4}$ & \\
\hline & $\mathrm{Km}^{2}$ & $\%$ & & $\mathrm{Km}^{2}$ & $\%$ \\
\hline Pastagem natural & $12.161,94$ & 77,13 & & $12.218,94$ & 65,49 \\
\hline Pastagem plantada & $3.605,184$ & 22,87 & & $6.438,64$ & 34,51 \\
\hline Total & $15.767,12$ & 100 & & $18.657,58$ & 100 \\
\hline
\end{tabular}

\section{Identificação dos fatores determinantes pelo modelo SAR}

Dos fatores potenciais determinantes listados na tabela 1, apresentaram correlação entre si acima do valor crítico seis (06) variáveis, saindo assim da análise: vilas, portos, densidade da população rural, rodovias estaduais e Unidade de Conservação federal de proteção integral. As demais entraram nos modelos com alternância entre os tipos de pastagens e anos.

A autocorrelação das variáveis dependentes foi confirmada pelo índice de Moran de $I=0,747, I=$ 0,749, para pastagem naturais em 2000 e 2014 e $I=0,637, I=0,680$ para pastagens plantadas, indicando que se o uso mudar em uma determinada área há uma tendência desse uso se propagar para áreas vizinhas.

A tabela 2 apresenta as variáveis determinantes para cada tipo de pastagem nos diferentes anos. Em 2000 o $R^{2}$ da pastagem natural foi de 0,781 enquanto para as pastagens plantadas foi de 0,638 . Esse mesmo comportamento é apresentado para o ano de 2014 com a variação somente na terceira casa decimal para pastagem natural, enquanto que para a pastagem plantada foi maior que em 2000 com valor de 0,680.

Os resultados da análise de regressão mostraram que a porcentagem de área com a agricultura e precipitação anual foram as variáveis explicativas que apresentaram ter influência sobre os dois tipos de pastagens nos dois anos analisados, embora os coeficientes para precipitação estejam muito baixos. Para as pastagens plantadas a variável explicativa mais significativa foi o percentual de estabelecimentos agropecuários com pecuária com coeficiente de -0,37 e 0,24 em 2000 e 2014, respectivamente. O objetivo desse estudo foi somente verificar quais fatores que possuem relações com as pastagens no Baixo Amazonas, não selecionando assim as variáveis que resultariam num melhor modelo explicativo com a inclusão ou remoção das mesmas. 
Tabela 2: Fatores determinantes das pastagens do modelo de regressão espacial spatial lag. Somente valores significativos $(p<0,05)$.

\begin{tabular}{|c|c|c|c|c|}
\hline \multirow[t]{3}{*}{ Variáveis explanatórias } & \multirow{2}{*}{$\begin{array}{l}\text { Pastagem Natural } \\
2000\end{array}$} & \multirow{2}{*}{$\begin{array}{l}\text { Pastagem Plantada } \\
2014\end{array}$} & \multirow[b]{2}{*}{2000} & \multirow[b]{2}{*}{2014} \\
\hline & & & & \\
\hline & Coeficientes & & & \\
\hline Constante & 0,0179 & 0,00976 & 0,01101 & 0,02439 \\
\hline $\mathrm{W}$ & 0.9295 & 0.9297 & 0.8272 & 0.8558 \\
\hline agricultura & $-0,0528$ & $-0,0436$ & 0.0146 & 0,05103 \\
\hline precipitação & $-4,34 \mathrm{e}-06$ & $-5,69 e-06$ & $-4,06 e-06$ & $-7,4 e-06$ \\
\hline Assentamentos rural & $-0,00721$ & 0,00443 & 0,003242 & - \\
\hline Cidade & - & $-1,11 \mathrm{e}-08$ & - & $-1,9 e-08$ \\
\hline Degradação florestal & - & - & $-0,2116$ & - \\
\hline Estabelecimentos agropecuários com pecuária & - & - & $-0,3717$ & 0,2368 \\
\hline Estradas & - & - & 0,01851 & - \\
\hline Gini da estrutura agrária & - & - & 0,003119 & $-0,01897$ \\
\hline Gini de renda & - & 0,01139 & - & 0,03528 \\
\hline Hidrovias & $-5,14 e-08$ & $-3,94 e-08$ & - & - \\
\hline IDHM & - & - & - & $-0,02002$ \\
\hline PIB & $-7,70 e-09$ & - & $-1,38 e-08$ & - \\
\hline Rodovias federais & - & - & - & $-3,7 e-08$ \\
\hline Terras indígenas & $-0,0048$ & - & - & - \\
\hline Unidade de Conservação Estadual de Proteção Integral & $-0,00387$ & - & - & - \\
\hline Unidade de Conservação Federal de Uso Sustentável & $-0,00636$ & 0,01121 & - & $-0,00501$ \\
\hline R-quadrado & 0,781 & 0,784 & 0,638 & 0,680 \\
\hline Log likelihood & 24714,9 & 24811,5 & 39558,9 & 33603,8 \\
\hline Akaike info criterion (AIC) & $-49409,7$ & -49605 & $-79099,8$ & $-67185,6$ \\
\hline
\end{tabular}

(-) indica que a variável não entrou no modelo de regressão espacial.

\section{DISCUSSÃO}

As áreas de pastagens aparecem concentradas nas regiões próximos a estradas e hidrovias. Esse fato pode ser atribuído a acessibilidade aos locais. Na Amazônia a frente de exploração está associada com aberturas de estradas onde se instalam vilarejos, projetos de assentamentos as proximidades de rodovias federais e estaduais, além de que o histórico de ocupação do território a instalação de sedes municipais e comunidade ribeirinhas localizadas as margens de cursos d'água (ESCADA et al., 2013). Na área de estudo, especificamente, as concentrações e o crescimento de áreas de pastagens plantadas estão próximos estradas, rodovias BR-163 (Cuiabá-Santarém) e BR-230 (Transamazônica).

Conforme a Tabela 1, no Baixo Amazonas as áreas de pastagens naturais são superiores as pastagens plantadas com 77,13\% em 2000 e 65,49\% em 2014. Enquanto as áreas de pastagens plantadas apresentaram um aumento de 11,64\% em 2014, quando comparado com as áreas de 2000 seguindo a tendência indicada pelos dados do censo agropecuário do IBGE para a região Norte, conforme Dias-Filho (2014). Contrapondose a média nacional em que as áreas de pastagens tiveram pouco crescimento desde 1970 até 2006 como consequência da expansão das áreas agrícolas, de reflorestamento e de urbanização sobre as áreas originais de pastagem.

Na Figura 4 é possivel observar a distribuição das pastagens naturais que estão concentradas nas áreas de influência do rio Amazonas, região de várzea que possuem plantas herbáceas que tem sido utilizada para a alimentação de rebanhos. De acordo com Sheik et al. (2006) a implantação de rebanhos bubalinos foi introduzida no Baixo Amazonas em 1950 com aproximadamente 160.000 de cabeças de gado ocupando campos naturais. Devido a dinâmica da planície de inundação, as pastagens naturais das áreas de várzea 
formaram a base forrageira apropriada para o gado e búfalos por ser altamente nutritivas para os rebanhos (SHEIK et al., 2006; CAMPHORA, 2016). No entanto, o baixo potencial produtivo das pastagens naturais devido a dinâmica de cheia e vazantes, além da política governamental de incentivos fiscais e de colonização na Amazônia, fizeram com que a pecuária se expandisse para áreas de pastagens cultivadas, refletindo assim um crescimento de áreas de pastagens plantadas no Baixo Amazonas (TOWNSEND et al., 2012).

A porção norte da mesorregião não apresenta cobertura com pastagem (Figura 4) isso pode ser justificado pela dificuldade de acessibilidade a esses pontos, além da presença da Estação Ecológica do Grão Pará e Reserva Biológica de Maicuru e grandes áreas com terras indígenas. Essas unidades de proteção tendem a dificultar a implantação/expansão das áreas de pastagens plantadas. Em outros pontos da área de estudo existem outras duas unidades de conservação federal de proteção integral e sete de uso sustentável: Floresta Nacional de Tapajós, Floresta Nacional de Mulata, Reserva Extrativista Tapajós Arapiuns, Floresta Nacional de Saracá-Taquera, Reserva Extrativista Renascer, Reserva Extrativista Riozinho do Anfrísio, Reserva Extrativista Verde Para Sempre.

De acordo com Almeida et al. (2016) as áreas de pastagens na Amazônia têm alta correlação com o desmatamento onde áreas com pastagens ocupam uma média de $62,1 \%$ de áreas desflorestadas. Ainda conforme esses autores e Espindola et al. (2012) outros estudos já sugeriram que a expansão da pecuária está entre os mais importantes responsáveis pelos desmatamentos na região amazônica, assim linkando pastagem, pecuária e desmatamento. Por isso, os determinantes das pastagens são muito similares aos drivers do desmatamento como estradas, assentamentos e outras variáveis de acessibilidade e mercado (AGUIAR, 2006, RIVERO et al., 2009; ESPINDOLA et al., 2012).

Nas duas datas (2000 e 2014) houve mudanças no número de variáveis explicativas entre os tipos de pastagens. A precipitação apresentou valores significativos em todos os anos e nos dois tipos de pastagens, embora seus coeficientes estejam muito baixos. Observa-se que a precipitação funciona com um fator natural para o crescimento das pastagens e de sua distribuição devido a um aspecto particular da região que é o volume anual de chuvas, que está em torno de 2.300 a $2.800 \mathrm{~mm}$ (MORAES et al., 2005), além disso, associados a temperatura quase constante $\mathrm{o}$ ano todo apresentam-se como fatores ambientais determinantes para as pastagens região Amazônica.

De acordo com Mertens et al. (2002) nem sempre a existência de pastagens está associada com a pecuária, sendo muitas vezes de outros processos territoriais, que ocorrem na Amazônia como a especulação fundiária, por exemplo. A concentração de terras é alta no Estado do Pará, sendo um dos Estados com maior desigualdade na distribuição de terras no país. Alguns municípios do Baixo Amazonas têm índice de Gini (ig) da estrutura agrária de média a forte $(0,5>i g<7,1)$, com exceção de Santarém que seu ig foi de 0,73 de acordo com os dados do censo agropecuário do IBGE de 2006. As relações das pastagens com a estrutura agrária foram verificadas na Tabela 2 com valores significativos de Gini de 0,003119 e -0,01897 e percentual de estabelecimentos agropecuários com pecuária de $-0,3717$ e 0,2368 paras as pastagens plantadas em 2000 e 2014, respectivamente. 
Os resultados apresentados podem dar o direcionamento das relações entre pastagens e os fatores determinantes, porém deve-se ressaltar que possíveis erros nos modelos devem ser considerados devido a as limitações da resolução espacial escolhida e escalas das fontes de dados. Por exemplo, a escala do mapeamento do uso e cobertura da terra do IBGE é de 250 metros, podendo conter misturas de classes de uso e cobertura dentro desse pixel. Além disso, dados temporais que possam ser utilizados para o mesmo período que as variáveis dependentes são escassas, fazendo com que não se capture a dinâmica ocorrida para aquela data específica. Ainda assim é possível se detectar os fatores mais importantes do processo mesmo com baixos valores nos resultados da regressão espacial. De acordo com Aguiar (2006) pode ocorrer mudanças somente na ordem de importância dos fatores embora não alterem mudanças significativa na composição dos fatores mais importantes.

\section{CONCLUSÕES}

Este estudo analisou a variação espacial da distribuição de pastagens e seus diferentes tipos de fatores determinantes no Baixo Amazonas usando a regressão espacial como método de análise. Observouse que as áreas de pastagens naturais ainda são em maior proporção que áreas de pastagens cultivadas. Verificou-se que as áreas de pastagens naturais aparecem concentradas nas áreas próximas ao Rio Amazonas, na planície de inundação, enquanto que as plantadas ocorrem próximos a estradas e rodovias. Além disso, outro resultado verificado foi as barreiras existentes na extensão da área de estudo tais como o estabelecimento de áreas protegidas, que atuam para impedir a expansão das áreas de pastagens plantadas.

O número de variáveis explicativas para cada tipo de pastagem nos anos de 2000 e 2014 variou, sendo a dimensão estrutura agrária a de maior coeficiente dentre as significativas para as pastagens cultivadas. A modelagem estatística e espacialmente explicita corroboram para análise e entendimentos dos fatores determinantes de mudanças no uso e cobertura da terra demonstrando ser uma ferramenta útil de análise para compreender os processos e padrões de mudanças de uso e cobertura da terra.

Os resultados aqui encontrados dão um direcionamento dos fatores determinantes das pastagens, além da compreensão da distribuição dos dois tipos, plantadas e naturais. A abordagem adotada neste estudo foi satisfatória para o alcance dos objetivos, porém outros métodos com a utilização de dados com resolução espacial melhores podem ser implementados para alcançar novos resultados, aliando dados de campo e modelagem estatística mais robustas.

\section{REFERÊNCIAS}

AGUIAR, A. P. D.. Modelagem de mudança do uso da terra na Amazônia: explorando a heterogeneidade intra-regional. Tese (Doutorado em Sensoriamento Remoto) - Instituto Nacional de Pesquisas Espaciais, São José dos Campos, 2006

AGUIAR, A. P. D.; CÂMARA, G.; ESCADA, M. I. S.. Spatial statistical analysis of land-use determinants in the Brazilian Amazonia: Exploring intra-regional heterogeneity. Ecological modelling, v.209, n.2-4, p.169-188, 2007. DOI:

http://doi.org/10.1016/j.ecolmodel.2007.06.019
AGUIAR, D. A.; MELLO, M. P.; NOGUEIRA, S. F.; GONÇALVES, F. G.; ADAMI, M.; RUDORFF, B. F. T.. MODIS Time Series to Detect Anthropogenic Interventions and Degradation Processes in Tropical Pasture. Remote Sensing, v.9, n.73, 2017. DOI: http://doi.org/10.3390/rs9010073

ALMEIDA, C. A.; COUTINHO, A. C.; ESQUERDO, J.C. D. M.; ADAMI, M.; VENTURIERI, A.; DINIZ, C. G; DESSAY, N.; DURIEUX, L.; GOMES, A. R.. High spatial resolution land use and land cover mapping of the Brazilian Legal Amazon in 2008 using Landsat-5/TM and MODIS data. Acta Amazonica, 
v.46, n.3, p.291-302, 2016. DOI:

http://dx.doi.org/10.1590/1809-4392201505504

ANSELIN, L.. Exploring spatial data wtih GeoDa TM: a workbook. University of Illinois, 2005.

BALDI, G.; PARUELO, J. M.. Land-Use and Land Cover Dynamics in South American Temperate Grasslands. Ecology and Society, v.13, n.2, 2008.

CAMPHORA, V. P.. Índice de antropização da várzea amazônica: uma proposta metodológica de integração de dados censitários e de sensoriamento remoto. Dissertação (Mestrado em Sensoriamento Remoto) - Instituto Nacional de Pesquisas Espaciais, São José dos Campos, 2016.

COSTA, W.; FONSECA, L.; KÖRTING, T.. Classifying Grasslands and Cultivated Pastures in the Brazilian Cerrado Using Support Vector Machines, Multilayer Perceptrons and Autoencoders. In: PERNER, P.. Machine Learning and Data Mining in Pattern Recognition. Lecture Notes in Computer Science, v.9166, p.187-198, 2015.

DIAS-FILHO, M. B.. Diagnóstico das Pastagens no Brasil. Belém: Embrapa Amazônia Oriental, 2014.

ESCADA, M. I. S.; DAL'ASTA, A. P.; SOARES, F. R.; ANDRADE, P. R.; PINHO, C.M. D.; MEDEIROS, L. C.C; CAMILOTTI, V. L.; SANTOS, J. N. A; FERREIRA, V. C.; AMARAL, S.. Infraestrutura, serviço e conectividades ribeirinhas do Arapiuns. São José dos campos: INPE, 2013.

ESPINDOLA, G. M.; AGUIAR, A. P.; PEBESMA, E.; CÂMARA, G.; FONSECA, L.. Agricultural land use dynamics in the Brazilian Amazon based on remote sensing and census data. Applied Geography, v.32, n.2, p.240-252, 2012. DOI: http://doi.org/10.1016/j.apgeog.2011.04.003

FAO. Grasslands of the World. In: SUTTIE, J. M.; REYNOLDS, S. G.; BATELLO, C.. Plant Production and Protection. Series n.34. Roma, 2005.

IBGE. Área e Densidade demográfica da unidade territorial. Brasil, 2010.

IBGE. Mudanças na cobertura e uso da terra 2000-20102012-2014. Rio de Janeiro, 2016.

MERTENS, B.; POCCARD-CHAPUIS, R.; PIKETTY, M. G.; LACQUES, A. E.; VENTURIERI, A.. Crossing spatial analyses and livestock economics to understand deforestation processes in the Brazilian Amazon: the case of Sao Felix do Xingu in South Para. Agricultural economics, v.27, n.3, p.269-294, 2002. DOI: http://doi.org/10.1016/S01695150(02)00076-2
MORAES, B. C.; COSTA, J. M. N.; COSTA, A. C. L.; COSTA, M. H.. Variação espacial e temporal da precipitação no estado do Pará. Acta Amazônica, v.35, n.2, p.207-214, 2005. http://dx.doi.org/10.1590/S0044-59672005000200010

PHELPS, L. N.; KAPLAN, J. O.. Land use for animal production in global change studies: Defining and characterizing a framework. Global Change Biology, v.23, n.11, p.4457-4471, 2017. DOI: http://doi.org/10.1111/gcb.13732

RIVERO, S.; ALMEIDA, O.; ÁVILA, S.; OLIVEIRA, W.. Pecuária e desmatamento: uma análise das principais causas diretas do desmatamento na Amazônia. Nova Economia, v.19, n.1, p.41-66, 2009.

SALA, O. E.; PARUELO, J. M.. Ecosystem Services in grasslands. Nature's Services: Societal Dependence on Natural Ecosystems. Washington: Island Press, 1997.

SHEIKH, P. A.; MERRY, F. D.; McGrath, D. G.. Water buffalo and cattle ranching in the Lower Amazon Basin:

Comparisons and conflicts. Agricultural Systems, v.87, n.3, p.313-330, 2006. Dol:

http://doi.org/10.1016/j.agsy.2005.02.003

SILVA, M.; NASCIMENTO, C. P.; COUTINHO, A. C.; ALMEIDA, C. A.; VENTURIERI, A.; ESQUERDO, J. C. S. M.. A transformação do espaço amazônico e seus reflexos na condição atual da cobertura e uso da terra. Novos Cadernos NAEA, v.16, n.1, p.229-248, 2013.

SILVA, P.; LI, L.. Mapping Urban Expansion and Exploring Its Driving Forces in the City of Praia, Cape Verde, from 1969 to 2015. Sustainability, v.9, n.8, p.1434, 2017. DOI: http://doi.org/10.3390/su9081434

THERY, H.. Situações da Amazônia no Brasil e no continente. Estudos Avançados, v.19, n.53, p.37-49, 2005.

TOWNSEND, C. R.; COSTA, N. L.; PEREIRA, R. G. A.. Pastagens Nativas na Amazônia Brasileira. Porto Velho: Embrapa Rondônia, 2012.

USDA. Department of Agriculture, Foreign Agricultural Service. Production, Supply and Distribution Online Data base. 2018.

XIE, Y.; SHA, Z.. Quantitative analysis of driving factors of grassland degradation: a case study in Xilin River Basin, Inner Mongolia. The Scientific World Journal, v.2012, n.2, 2012. DOI: http://doi.org/10.1100/2012/169724

ZIMMER, A. H.; MACEDO, M. C. M.; KICHEL, A. N.; ALMEIDA R. G.. Degradação, recuperação e renovação de pastagens. Campo Grande: Embrapa Gado de Corte, 2012.

A CBPC - Companhia Brasileira de Produção Científica (CNPJ: 11.221.422/0001-03) detém os direitos materiais desta publicação. Os direitos referem-se à publicação do trabalho em qualquer parte do mundo, incluindo os direitos às renovações, expansões e disseminações da contribuição, bem como outros direitos subsidiários. Todos os trabalhos publicados eletronicamente poderão posteriormente ser publicados em coletâneas impressas sob coordenação da Sustenere Publishing, da Companhia Brasileira de Produção Científica e seus parceiros autorizados. Os (as) autores (as) preservam os direitos autorais, mas não têm permissão para a publicação da contribuição em outro meio, impresso ou digital, em português ou em tradução. 